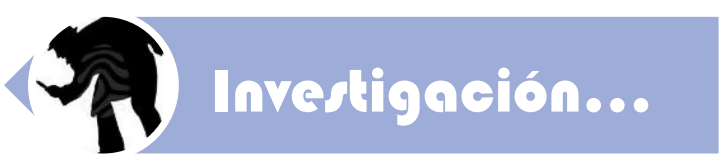

\title{
DIFERENGIAS DE RIESGOS PSICOSOCIALES ENTRE DOS COLEGIOS, UNO ESTRATO BAJO Y OTRO ESTRATO ALTO
}

Investigadores de campo: Acevedo GC, Arias AC, Arias D, Angarita G, Barbosa J. Acosta $E$, Alvarado $A$, Arias YP, Balaguera Y, López Y, Amézquita D, Ayala LD, Barragán AA, Bello LL, Benavides T, Benitez DM, Achury JD, Ariza M, Arrieta LF, Balanta MC§

Tutor de la investigación y editor: Juan Carlos González** Análisis estadístico y colaboración: Jenny Pinzón.

Dibujos Andrés Reyes.

\section{RESUMEN}

Objetivo: Identificar si existen diferencias de riesgos psicosociales entre dos colegios, con predominio de estratos dos y cuatro, respectivamente.

Metodología: Se aplicó una encuesta autodiligenciada en la que se interrogó sobre conocimientos, actitudes y comportamientos de riesgo psicosocial y la estructura y percepción del funcionamiento familiar.

Tipo de estudio: Descriptivo de tipo corte.

Población: 1.255 adolescentes de sexto a undécimo grado pertenecientes a dos colegios, uno privado y uno público.

Resultados: Todas las razones de posibilidades comparadas mostraron mayor riesgo en al colegio estrato dos versus el cuatro. Creer que el condón protege contra el SIDA (OR 0,3 IC $95 \% 0,2-0,6$ ). Tener relaciones sexuales (OR 2,3 IC $95 \%$ 1,6-3,4). Protección en la primera relación sexual (OR 0,3 IC 95 \% 0,1-0,6). Riesgo de TCA (OR 1,8 IC $95 \%$ 1,3-2,5). Golpeó a alguien en el último año (OR 1,5 IC $95 \% 1,1-2,1$ ). Llevar un arma para defenderse (OR 8,9 IC $95 \%$ 1,2-66,1). Beber la última semana (OR 0,4 IC $95 \% 0,3-0,5)$. Fumar en la actualidad (OR 0,2 IC $95 \% 0,1-0,3$ ).

Conclusión: Esta investigación demuestra una situación de inequidad social que motiva a la reflexión.

Palabras claves: Adolescente, conducta del adolescente, conducta de riesgo, conducta sexual, violencia, trastornos de alimentación y de la ingestión de alimentos, problemas sociales, inequidad social (fuente: DeCS).

\begin{abstract}
Objective: To identify psychosocial risks differences between a school of socioecomic strata 4 (upper) and a school of socioecomic strata 2 (lower).

Methodology: A self-questionnaire was administered. The questionnaire asked about knowledge, attitudes and, behaviors related to psychosocial risks. Also it was inquired about family structure and perception of family functionality.

Population: Students in $6^{\text {th }}$ to $11^{\text {th }}$ grade attending a private school and a public one (socioeconomic strata 45 and 2, respectively).

Results: All the compared odds ratio showed higher risk in the lower strata school. Believing condom protects against HIV (OR 0,3 CI $95 \%$ 0,2-0,6). Having intercourse (OR 2,3 CI $95 \% 1,6-3,4$ ). Protection in the firsttime sex (OR 0,3 CI $95 \%$ 0,1-0,6). Eating disorder risk (OR 1,8 CI $95 \%$ 1,3-2,5). Hitting someone last year (OR 1,5 CI $95 \% 1,1-2,1$ ). Carrying a weapon to defend yourself (OR 8,9 CI $95 \% 1,2-66,1$ ). Drinking last week (OR 0,4 CI $95 \% 0,3-0,5$ ). Smoking currently (OR 0,2 CI $95 \% 0,1-0,3$ ).

Conclusion: This research demonstrates a social inequality that motivates reflection.

Key words: Adolescent, adolescent behavior, risk-taking, sexual behavior, violence, feeding and eating disorders, social problems, social inequity (source: $\mathrm{MeSH}$ ).

$\S \S$ Estudiantes VII semestre 2016 (Investigación Social 2). Facultad de Medicina, FUJNC.

** MD. Especialista Medicina Familiar Integral, MSP. Director Departamento de Medicina Comunitaria juan.gonzalez@juanncorpas.edu.co
\end{abstract}




\title{
INFORME FINAL
}

\author{
Introducción
}

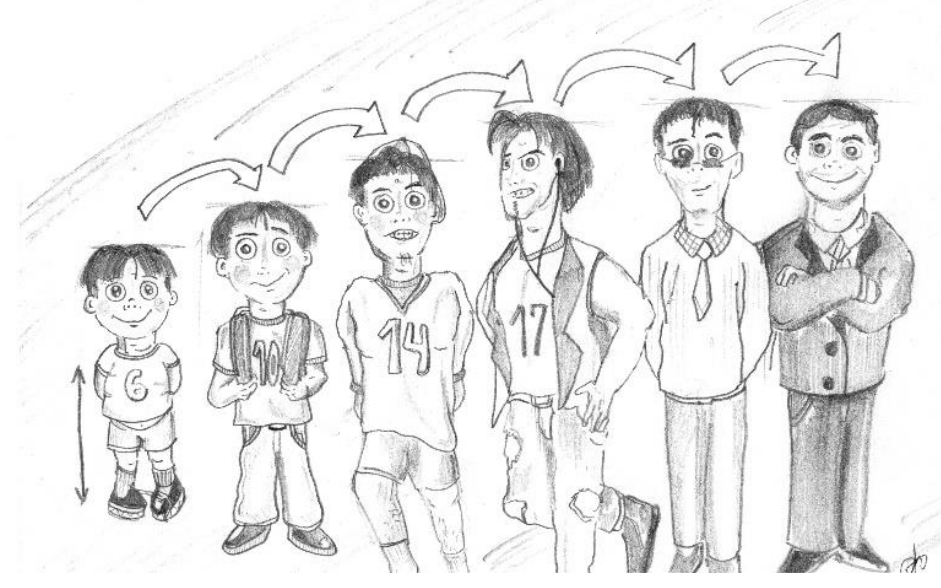

Adolescencia, momento clave en la existencia por ser ahí donde el joven se enfrenta a la toma de decisiones y, por ende, al riesgo derivado de las mismas. Se ha definido el término factor de riesgo (1) como "probabilidad que suceda un evento adverso en un tiempo determinado". Aspectos del entorno (condición socioeconómica), los relacionados con la sexualidad (comportamientos y conocimientos, por ejemplo), con la convivencia y, los factores emocionales y psíquicos del joven (trastornos de conducta alimentaria), así como el contacto y consumo con sustancias como alcohol y tabaco, necesitan ser estudiados de forma insistente y dinámica, esperando con esto acercarnos más al entendimiento del mundo de los adolescentes, para que de ahí surjan propuestas (2) que confirmen que es "mejor" invertir en el joven que en las "secuelas adversas" que se presentan en la adultez.

Desde principios de los tratados de Aristóteles sobre el deseo sexual hasta las teorías del desarrollo
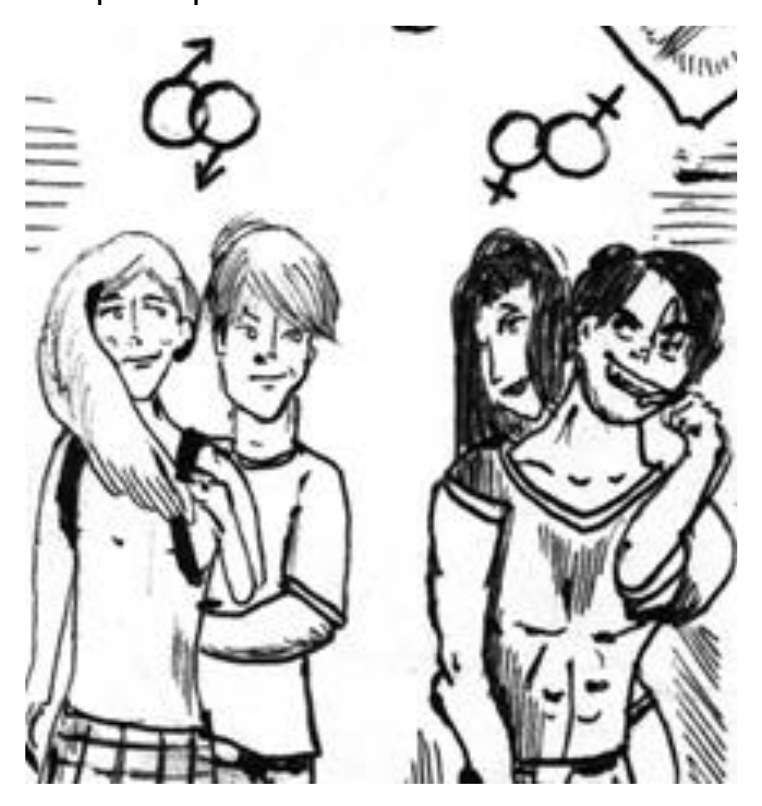
psicosocial de Sigmund Freud, la sexualidad de los adolescentes ha sido un tema controvertido para prácticamente todas las generaciones. En la medida en que avance el siglo XXI, la sociedad continuará siendo desafiada por el comportamiento sexual de los adolescentes y sus consecuencias. Aunque los médicos suelen tratar la sexualidad de los adolescentes en términos de "riesgo", es importante recordar que la sexualidad, las conductas sexuales y las relaciones sexuales son una parte importante y necesaria del desarrollo humano (3). Los principales riesgos son el contagio de infecciones de trasmisión sexual y el embarazo no deseado. El inicio tardío de la vida sexual y el uso de anticonceptivos como el condón, son factores determinantes para contrarrestar dichos riesgos. Es un método cercano al ideal pues, además, puede reducir el número de embarazos no deseados, y así, mejorar la calidad de vida de los jóvenes, social y físicamente (4). 


\section{Jóvenes y anticoncepción en Colombia}

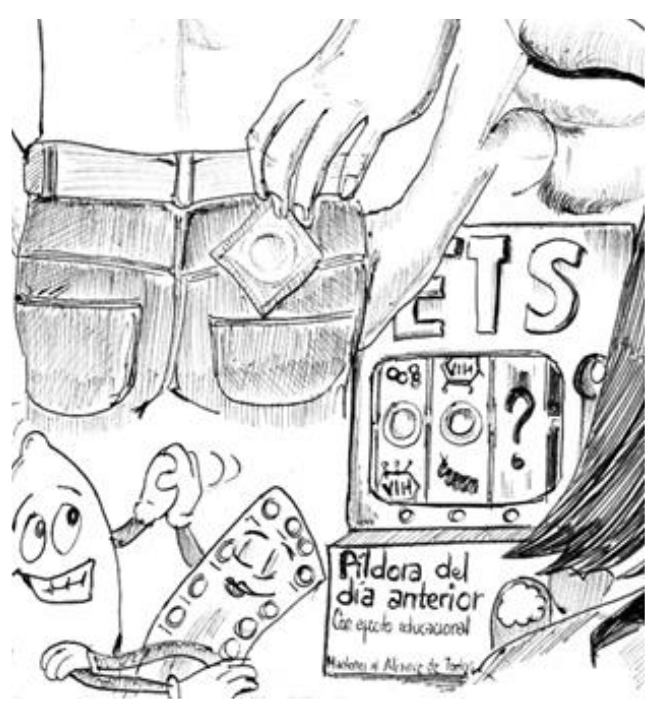

En Colombia la evidencia muestra un conocimiento generalizado de los métodos modernos de anticoncepción con cifras que reflejan que el 99,8 \% de las mujeres están al tanto de por lo menos un método de planificación según la Encuesta Nacional de Demografía y Salud 2010 (ENDS) (5). En cuanto a la demanda de planificación por parte de la población adolescente, para el 2004, según Flórez y otros (6), era similar en zonas urbanas y rurales, 83 y $80 \%$, respectivamente. Aun así, en la ENDS 2010 se indica que, en Colombia, la "demanda insatisfecha es mayor en el grupo de 15 a 19 años de edad, donde llega al $20 \%$, demostrando la necesidad de más y mejores programas de información y servicios para jóvenes o adolescentes" (5).

\section{Diferencias}

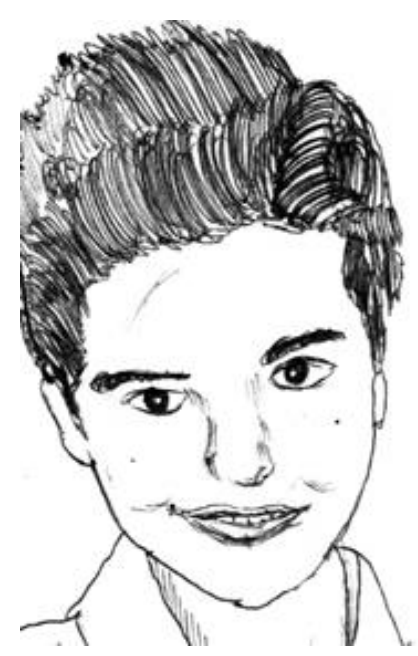

En Colombia, distinguiendo por nivel socioeconómico, existe una importante diferencia entre los estratos alto y bajo en cuanto al uso de métodos anticonceptivos. Según cálculos basados en el ENDS 2010 , en los estratos más altos el uso del condón en la primera relación tuvo una prevalencia mayor (no uso: $34 \%$ y persistencia en el no uso: $9 \%$ ) con relación al estrato más bajo (no uso: 60 \% y persistencia en el no uso: $22 \%$ ) (7). 


\section{Violencia juvenil}

La OMS se refiere a la violencia juvenil como "un problema de salud pública, el cual incluye actos que van desde la intimidación y las riñas hasta el homicidio, pasando por agresiones sexuales y físicas más graves (8).

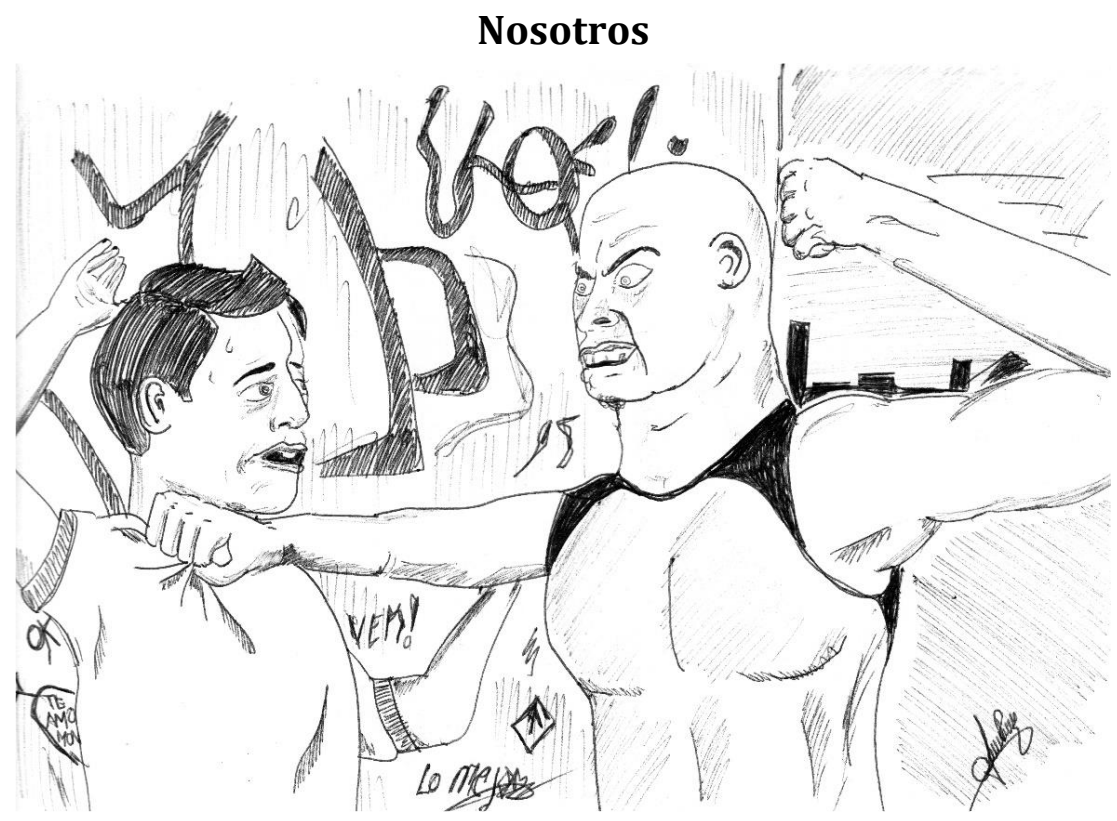

El estudio de convivencia escolar del DANE (9) de 2011 mostró que un 37,2 \% de los estudiantes de $5^{\circ}$ a $11^{\circ}$ grado de establecimientos oficiales $(23,9 \%$ en colegios privados) expresan haber visto que algunos de sus compañeros llevaron armas blancas al colegio mientras que el $41,3 \%$ de estudiantes de colegio privado manifestaron no haber observado este comportamiento. A su vez, el 3,9 \% de estudiantes en colegio oficial afirman que alguno de sus compañeros llevó armas de fuego mientras que en colegios privados solo el 2,1\% afirmó haber visto esta misma situación.

\section{Tratando de entender}

Briceño (10) buscó explicaciones de por qué países como Colombia, México y Brasil tienen tasas de violencia mucho más altas que Uruguay, Argentina, Chile y Costa Rica, y concluye que la diferencia de mortalidad entre los países se debe a los contextos sociales de cada país y a sus modelos políticos. Plantea que existen factores originarios, donde destacan las condiciones sociales, que, en el caso de los países latinoamericanos, se caracterizan por tener niveles altos de inequidad, pobreza y desempleo de personas jóvenes, todo esto asociado a la pérdida de mecanismos sociales tradicionales de control como lo son la familia y la religión. Menciona la cultura de masculinidad, el mercado de drogas y la ineficiencia de los sistemas judiciales que propician la impunidad. Por ello los puntos de concentración de violencia son áreas urbanas donde la elevada densidad poblacional y la pobre planeación en desarrollo propician la rápida aparición de zonas de exclusión caracterizadas por la escasa conexión con otras áreas, dificultades topográficas y poco acceso a los servicios (electricidad, agua, etc.), dichos factores favorecen el desarrollo de pandillas y grupos subversivos que buscan el control de estas zonas. Las diferencias de género muestran que los hombres son los que usualmente se ven implicados en los actos de violencia, hecho respaldado por la cultura de masculinidad donde son ellos los que tienen que confrontar a otros tras ser desafiados y así ganar respeto por sus pares. 
En cuanto a los mercados de drogas, en donde Brasil y Colombia resaltan, la búsqueda de nuevos lugares de venta y la competencia entre los ya establecidos se asocian al comercio ilegal de estas sustancias y de armas. Por último, la ineficiencia de los sistemas judiciales que propician la impunidad hace que los perpetradores de violencia no tengan miedo de padecer frente a la ley porque saben que no van a ser castigados, a esto se le suma el hecho de que existe un hacinamiento en los sitios de retención, razón para dejarlos salir. Estos factores facilitadores se relacionan con las normas sociales que promueven el consumo de alcohol y la tendencia a cargar armas de fuego.

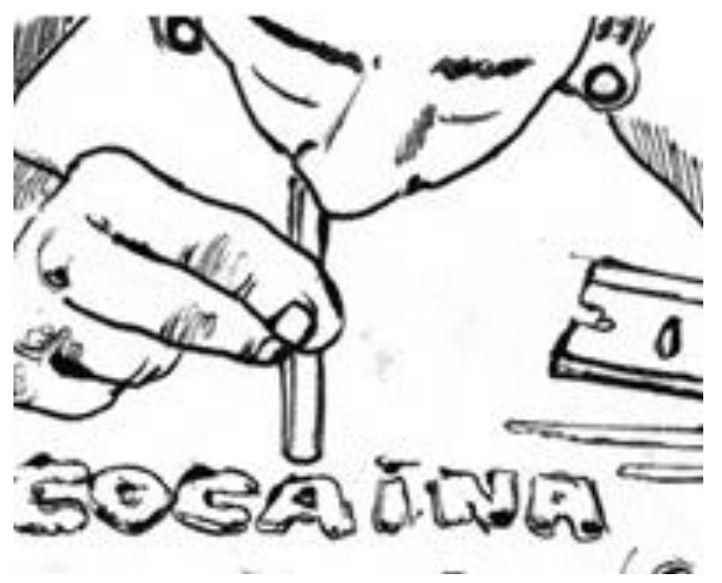

En su estudio Logan (11) analiza las características comunes entre jóvenes con comportamiento violento, con ideación o comportamiento suicida y que portan armas, entre las que se destacan como factores de riesgo el ser de sexo masculino, ser menor de 16 años, en algunos casos ser de raza 0 etnia no blanca (distinguiéndola de los hispanos, los negros no hispanos y otras minorías), presentar síntomas de depresión, el usar sustancias ilícitas y el tener amigos que se dedican a la delincuencia, marcando una diferencia significativa estos dos últimos factores. Como factores protectores se establecen el tener un vínculo fuerte con el colegio y el ser supervisados y cuidados por los padres.

Ruggles (12) observó que la tendencia que presentan algunos jóvenes de portar un arma, tiene una relación estrecha con el alcohol, el tabaco, el cigarrillo y otras drogas, datos que fueron constantes en todos los años del estudio. También se encontraron relaciones con otros sucesos como haber sido víctimas de acoso sexual, tener ideas suicidas, sentirse triste o sin esperanza, tener desórdenes alimentarios y haber estado recientemente con un conductor ebrio.

\section{Lo injusto}

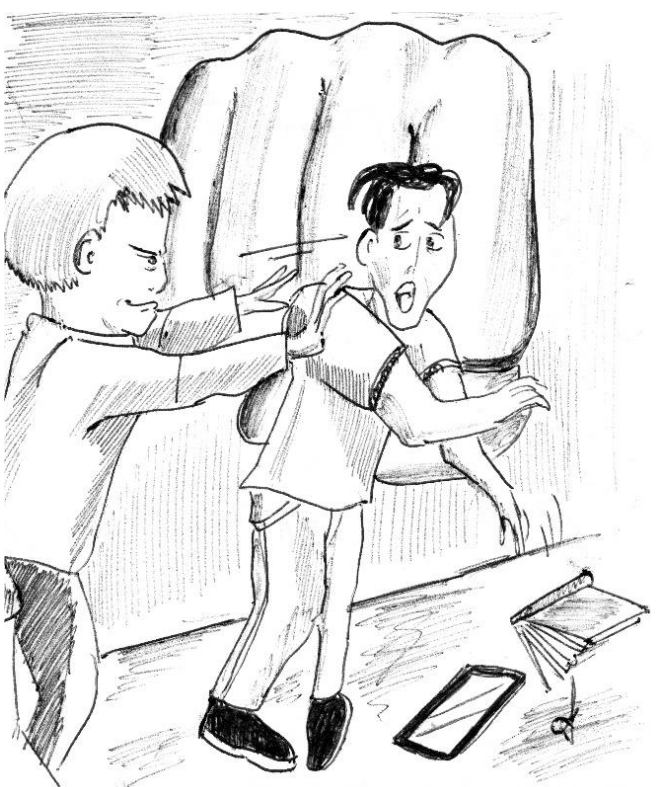

Pickett y otros (13) analizaron las tendencias epidemiológicas de la violencia física durante tres momentos distintos en 30 países principalmente europeos y norteamericanos. Su investigación muestra como factores de riesgo individuales el ser de sexo masculino, ser menor de 15 años, involucrarse en múltiples situaciones de riesgo y ser víctima frecuente de intimidación. En cuanto a los posibles determinantes socioeconómicos, el estudio identifica el índice nacional de homicidios, el crecer en países pobres (menor PIB per cápita) o vivir en contextos violentos.

Por otro lado, Sharma y otros (14) parten del hecho de que presenciar violencia entre los padres y ser víctimas de bullying son situaciones que desafortunadamente viven los niños y adolescentes todos los días. Con esto como base, estudiaron el rol de estos factores en la participación de violencia física entre adolescentes peruanos y concluyeron que los jóvenes de sexo masculino que han sido víctimas de bullying verbal y han presenciado violencia contra sus padres hombres y las jóvenes que han sufrido bullying, son los que más riesgo tienen de verse involucrados en peleas. 


\section{Los trastornos de conducta alimentaria}

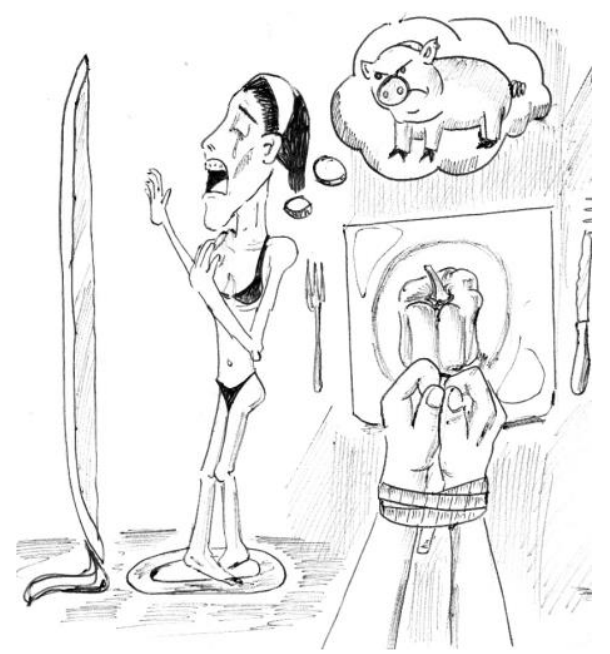

Quienes padecen de trastornos de conducta alimentaria (TCA) se caracterizan por tener una poca aceptación de su cuerpo y por su deseo de estar delgados, todo esto causado, generalmente, por una baja autoestima. Estos trastornos están asociados también a problemas de cognición y conductas en el control del peso, provocando no solo un cambio a nivel físico sino además llevando a complicaciones biológicas, psicológicas y sociales (15). Aunque pueden afectar a cualquier tipo de persona, sin importar su edad o género, se ha demostrado que alrededor del $95 \%$ de las personas que padecen de estos trastornos son adolescentes de sexo femenino y adultas jóvenes. Los hombres presentan menor incidencia, pero, cuando cursan con esta patología, suele ser aún más complicada (16).

\section{Recordar}

El Manual Diagnóstico y Estadístico de los Trastornos Mentales IV (DSM por sus siglas en inglés) clasifica TCA en bulimia nerviosa y anorexia nerviosa y, se habla de una tercera clasificación, la obesidad simple (17), que se encuentra en la Clasificación Internacional de Enfermedades (CIE), aunque no en el DSM IV.

Los TCA constituyen un problema de salud pública por su creciente incidencia cada vez en edades más tempranas y por la dificultad en su tratamiento; se dice que es un problema que afecta a cualquier sociedad. La anorexia y la bulimia conducen a la muerte en el $6 \%$ de los casos y la prevalencia oscila entre el 0,5 y el $1 \%$ de acuerdo al DSM IV (2002) (18). En la mayoría de los casos descritos en adolescentes y jóvenes, se observa una tendencia a tener escasa conciencia de la enfermedad, muchas veces ni los padres de familia notan estos cambios y terminan visitando al médico por una segunda causa como el sobrepeso, las alteraciones menstruales en el caso de mujeres o el estreñimiento en búsqueda de laxantes.

Los medios de comunicación influyen de manera directa en la autoestima de la persona al establecer un modelo ideal de belleza que es compartido socialmente. Aramburu (19) definió la autoestima como "una especia de sociómetro que indica el grado en que una persona se percibe como incluida o excluida en el entramado social".

Unikel (20) menciona que la insatisfacción corporal, la excesiva preocupación por el peso y los trastornos alimentarios han venido incrementándose de manera consistente en los colegios. Montero (21) indica que la percepción de la imagen corporal puede ser bastante complicada para los adolescentes debido a que socialmente existe la creencia de que un cuerpo delgado es el ideal en el caso de la mujer y, musculoso, en el del hombre. 


\section{Las diferencias}

El consumo de sustancias psicoactivas en niños y adolescentes es un problema global de larga data que parece estar empeorando progresivamente con el tiempo. El continente americano y principalmente Latinoamérica, se han caracterizado como las zonas mayormente afectadas por el consumo nocivo de alcohol a nivel mundial (22), donde Colombia no es la excepción. Culturalmente en nuestro país, principalmente en las regiones rurales, el consumo de alcohol es aceptado y visto como algo común, normal y la mayoría de eventos sociales son acompañados por el alcohol. Es así que, en promedio, la edad de inicio para el consumo de alcohol y cigarrillo son los 12 años y el de marihuana se estima en los 14 años (23).

La problemática radica en que los menores de edad consumen alcohol (y/o tabaco y diversas sustancias psicoactivas) sin un control estricto para la venta y compra de este, siendo esta una situación social persistente. En el año 2006 El Tiempo (24) describió públicamente la

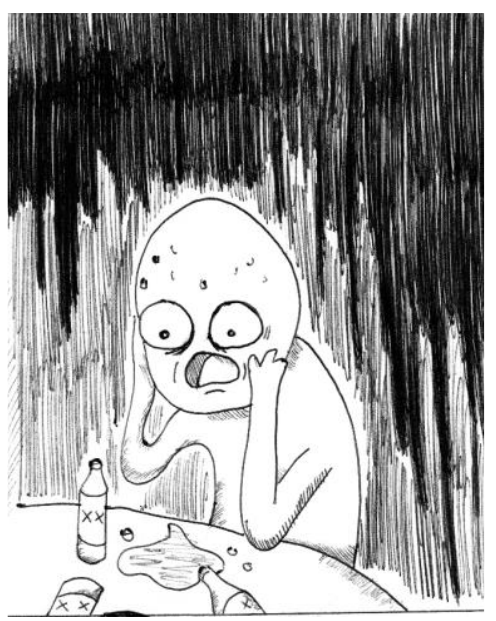
tendencia de los menores de edad a asistir a las denominadas "chiquitecas", entendidas estas como fiestas que se llevan a cabo de dos de la tarde a siete de la noche, especialmente los fines de semana, en las que los adolescentes se reúnen con el fin de socializar con otros y bailar reggaetón. Las autoridades encontraron que la mayoría de los sitios donde se realizaban dichas fiestas facilitaban el acceso al consumo de alcohol y cigarrillo. En Bogotá, en marzo y abril de ese mismo año la Policía Metropolitana selló 17 establecimientos en las localidades de Kennedy, Antonio Nariño, Usme y Restrepo, por la venta ilegal de alcohol y de cigarrillos a menores de edad. La influencia social y la curiosidad, parecen ser los factores determinantes sin importar la condición social (25).

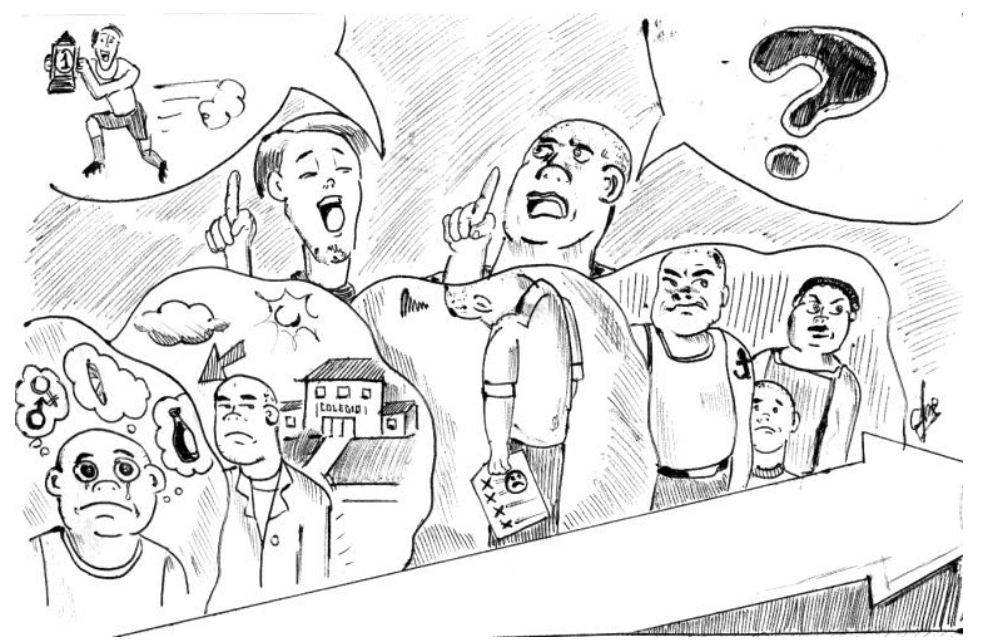

Sigampa (26) propone que, si algo puede ser útil para combatir todos estos factores de riesgo en los jóvenes, y el caso del alcohol no es una excepción (27), es la promoción de la autoestima. En tal sentido, distintos estudios proponen trabajar con la familia (28) unida con el entorno escolar.

Dado el contexto social antes descrito, la presente investigación quiso estimar las diferencias entre comportamientos de riesgo psicosociales de jóvenes escolarizados en un colegio con predominio de estrato dos (condición socioeconómica baja) con otro de estratos cuatro y cinco en su mayoría (condición socioeconómica medio-alta) buscando con esto poner en evidencia la desigualdad (si es que se encuentra) y promover intervenciones que promuevan la equidad en los programas de salud escolar. 


\section{MATERIALES Y MÉTODOS}
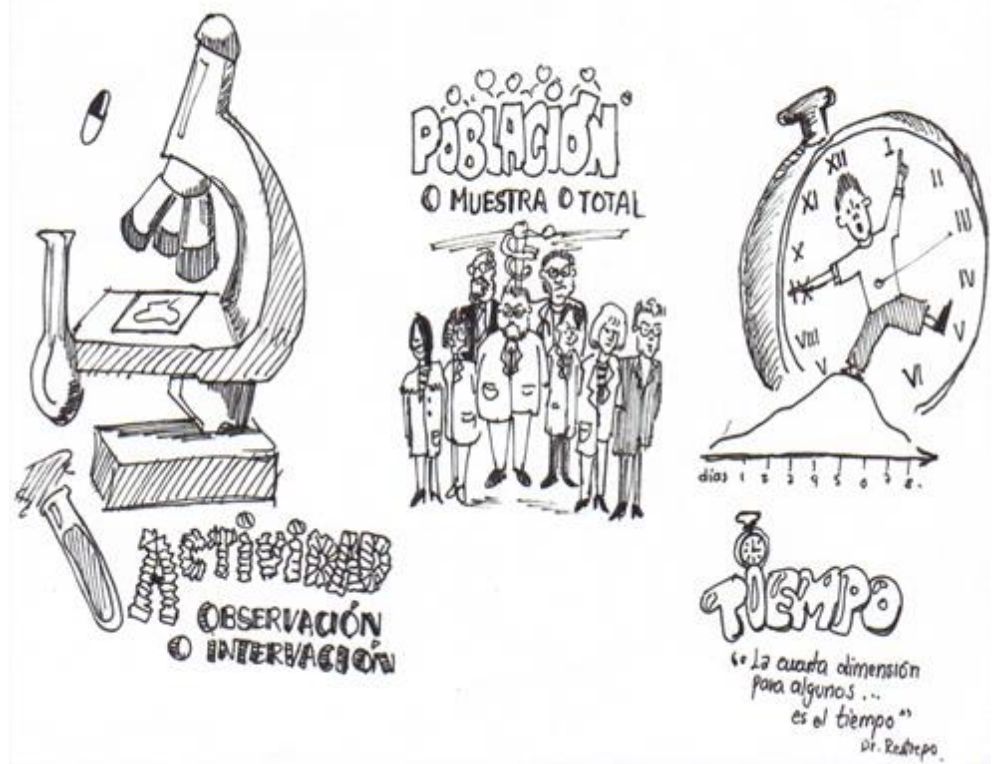

Tipo de estudio: Descriptivo de tipo corte transversal.

Población: Estudiantes de grado sexto a undécimo, con edades comprendidas entre los 10 y los 20 años, de un colegio público con predominio de estrato dos y un colegio privado mayormente con estratos cuatro y cinco de la localidad de Suba en Bogotá.

Criterios de inclusión: Estudiantes que pertenecieran a las instituciones educativas, que tuvieran autorización de los padres y que quisieran realizar de forma voluntaria la encuesta.

Variables de estudio: Se indagó por características demográficas (edad, sexo, lugar que ocupa en el hogar, estado de ánimo al momento de aplicar una encuesta, estrato, personas con las que vive). Variables acerca de la percepción familiar (test de APGAR original -apoyo, participación, afecto, tiempo compartido y comodidad- que se clasifica como función familiar normal, disfunción leve y disfunción severa). Estructura familiar, verificando presencia de hogares nucleares (padre, madre e hijos), incompletos (falta uno de sus padres), extensos (padres, hijos y otros familiares). Se indagó en torno a sexualidad si cree que el condón protege contra el SIDA, si ha tendido relaciones sexuales, edad de inicio de la vida sexual, protección en la primera relación, uso del método de protección en primera relación. Sobre convivencia, haber sido o haber golpeado a alguien en el último año, llevar un arma para defenderse. Para detectar riesgo de trastornos de conducta alimentaria se aplicó el test de SCOFF. Sobre consumo, haber bebido la última semana, haber fumado y tener amigos que consumen.

Manejo estadístico: Se tabularon los datos obtenidos en el programa Excel para obtener las frecuencias. De cada pregunta se obtuvo el porcentaje contestado. Se cruzaron los datos obtenidos tanto del colegio público como del privado, para la posterior obtención de los OR y el análisis de los mismos a través del programa Epi Info.

Recolección de la información: Se aplicó la encuesta "Conociéndome a mí mismo (2016)", de forma autodiligenciada, la cual incluye 52 preguntas, a estudiantes que cursaban los grados sexto a undécimo en dos colegios en Bogotá (privado y público). Previo a la aplicación de la encuesta se solicitó el debido permiso en cada institución, se aseguró a los estudiantes la confidencialidad de la información proporcionada y se explicó el diligenciamiento de la encuesta, aclarando las dudas respectivas. 


\section{RESULTADOS}

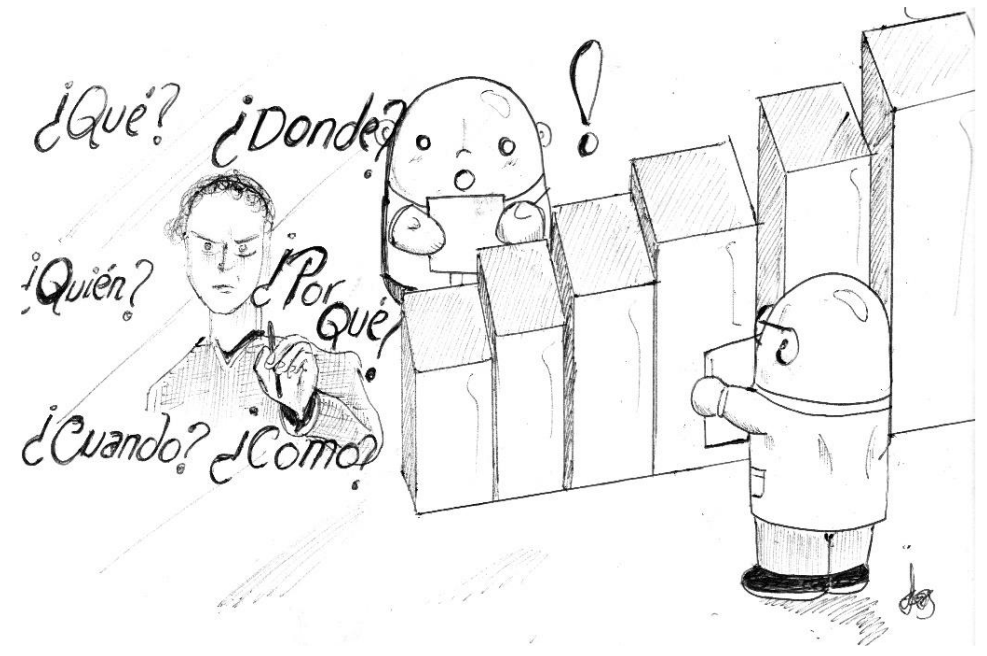

La media de edad del colegio con predominio de estrato 2 es de 14,1 ( $\pm D E 2,07)$ y la del colegio de estratos en su mayoría 4 y 5 es de 13,7 ( \pm DE 2,1).

Tabla 1. Características sociodemográficas y de función y estructura familiar de adolescentes de dos colegios, uno público y otro privado, en 2016.

\begin{tabular}{|c|c|c|c|c|}
\hline \multirow[t]{2}{*}{ VARIABLE } & \multicolumn{2}{|c|}{ IED } & \multicolumn{2}{|c|}{$\begin{array}{l}\text { Colegio } \\
\text { Privado }\end{array}$} \\
\hline & $\mathbf{N}^{\circ}$ & $\%$ & $\mathbf{N}^{\circ}$ & $\%$ \\
\hline \multicolumn{5}{|l|}{ Edades } \\
\hline De 10 a 12 años & 207 & 21 & 91 & 32 \\
\hline De 13 a 16 años & 665 & 69 & 165 & 58 \\
\hline De 17 a 20 años & 92 & 10 & 29 & 10 \\
\hline \multicolumn{5}{|l|}{ Sexo } \\
\hline Masculino & 458 & 47 & 164 & 57 \\
\hline Femenino & 511 & 53 & 122 & 43 \\
\hline \multicolumn{5}{|l|}{ Estrato } \\
\hline Estratos 1 y 2 & 684 & 76 & 3 & 1 \\
\hline Estratos 3 y 4 & 209 & 23 & 187 & 68 \\
\hline Estratos 5 y 6 & 9 & 1 & 85 & 31 \\
\hline \multicolumn{5}{|l|}{ Percepción del ánimo } \\
\hline Triste & 56 & 6 & 15 & 5 \\
\hline Feliz & 323 & 34 & 92 & 32 \\
\hline Normal & 584 & 61 & 177 & 62 \\
\hline \multicolumn{5}{|l|}{ Funcionalidad familiar } \\
\hline Disfunción severa & 51 & 5 & 8 & 3 \\
\hline Disfunción moderada & 257 & 27 & 59 & 21 \\
\hline Funcionalidad normal & 647 & 68 & 218 & 76 \\
\hline \multicolumn{5}{|l|}{ Estructura familiar } \\
\hline $\begin{array}{l}\text { Hogar nuclear (vive con papá, mamá y } \\
\text { hermanos) }\end{array}$ & 474 & 49 & 176 & 61 \\
\hline Hogar incompleto (falta uno de los padres) & 312 & 32 & 79 & 27 \\
\hline Hogar extenso (padres, hermanos y otros) & 79 & 8 & 23 & 8 \\
\hline Hogar reconstituido (padrastro y madrastra) & 41 & 4 & 4 & 1 \\
\hline Hogar sin padres & 61 & 6 & 6 & 2 \\
\hline
\end{tabular}

Como se observa en la tabla 1, existe más población femenina encuestada en el colegio público. Los hogares nucleares en el colegio público presentan un $12 \%$ menos respecto al colegio privado y existen más hogares reconstituidos y sin padres en el colegio de mayoría estrato 2. 
Tabla 2. Actitudes, comportamientos y conocimientos de sexualidad, comportamientos violentos, riesgo de trastornos de conducta alimentaria y comportamiento en torno al alcohol y al tabaco de adolescentes de dos colegios, uno con predominio de estrato 2 y otro, en su mayoría, de estrato 4 , en 2016.

\begin{tabular}{|c|c|c|c|c|}
\hline \multirow[t]{2}{*}{ VARIABLE } & \multicolumn{2}{|c|}{$\begin{array}{l}\text { COLEGIO } \\
\text { PREDOMINIO } \\
\text { ESTRATO } 2\end{array}$} & \multicolumn{2}{|c|}{$\begin{array}{l}\text { COLEGIO } \\
\text { PREDOMINIO } \\
\text { ESTRATO } 4\end{array}$} \\
\hline & $\mathbf{N}^{\circ}$ & $\%$ & $\mathbf{N}^{\circ}$ & $\%$ \\
\hline \multicolumn{5}{|l|}{ Sexualidad } \\
\hline \multirow{2}{*}{\multicolumn{5}{|c|}{$\begin{array}{l}\text { Actitudes } \\
\text { ¿Cree que usar el condón protege contra el } \\
\text { SIDA? }\end{array}$}} \\
\hline & & & & \\
\hline Sí lo cree & 326 & 34 & 121 & 43 \\
\hline No está seguro & 357 & 38 & 108 & 39 \\
\hline No lo cree & 125 & 13 & 16 & 6 \\
\hline No sabe & 140 & 15 & 35 & 13 \\
\hline \multicolumn{5}{|l|}{ Comportamientos } \\
\hline Tener o haber tenido relaciones sexuales & 247 & 26 & 37 & 13 \\
\hline Edad promedio del inicio & 14,1 & & 14,8 & \\
\hline No usó protección en primera relación sexual & 138 & 15 & 8 & 3 \\
\hline \multicolumn{5}{|l|}{ Método de planificación en primera relación } \\
\hline Condón & 126 & 14 & 28 & 10 \\
\hline Otro método & 46 & 5 & 0 & 0 \\
\hline \multicolumn{5}{|l|}{ Comportamientos violentos } \\
\hline Ha sido golpeado en último año & 283 & 31 & 82 & 29 \\
\hline Golpeó (pelea) a alguien el último año & 279 & 31 & 64 & 22 \\
\hline Lleva un arma rutinariamente para defenderse & 26 & 3 & 1 & 0 \\
\hline Lleva un arma ocasionalmente para defenderse & 81 & 9 & 11 & 4 \\
\hline \multicolumn{5}{|l|}{ Riesgos de TCA } \\
\hline Riesgo de trastorno de conducta alimentaria & 236 & 26 & 48 & 17 \\
\hline Se provoca el vómito después de comer & 81 & 9 & 13 & 5 \\
\hline $\begin{array}{l}\text { Le preocupa haber perdido control en forma de } \\
\text { comer }\end{array}$ & 293 & 33 & 71 & 25 \\
\hline $\begin{array}{l}\text { Ha perdido más de } 7 \text { kilos en los últimos tres } \\
\text { meses }\end{array}$ & 133 & 15 & 12 & 4 \\
\hline $\begin{array}{l}\text { Cree que está gordo(a) así los demás le digan } \\
\text { que está delgado(a) }\end{array}$ & 169 & 19 & 52 & 18 \\
\hline \multicolumn{5}{|l|}{ Consumo de alcohol y tabaco } \\
\hline Bebió la última semana & 291 & 30 & 40 & 14 \\
\hline Ya probó el cigarrillo & 274 & 32 & 42 & 16 \\
\hline Ya probó el alcohol & 488 & 55 & 159 & 58 \\
\hline Ya probó la marihuana & 172 & 21 & 18 & 7 \\
\hline Amigos beben o consumen SPA con frecuencia & 516 & 56 & 113 & 41 \\
\hline Fuman en la actualidad & 137 & 15 & 7 & 3 \\
\hline Fumador que le gusta fumar & 63 & 7 & 5 & 2 \\
\hline Bebe y le gusta & 185 & 20 & 40 & 14 \\
\hline
\end{tabular}


Tabla 3. Odds ratios entre adolescentes de colegios con estratos bajo y alto, respectivamente, de percepciones de uso del condón, tener relaciones sexuales, protección en la primera relación, haber sido golpeado o haber golpeado en el último año, llevar un arma para defenderse, riesgo de TCA, beber en la última semana, probar tabaco y alcohol, tener amigos que beben, obtenidos en 2016.

\begin{tabular}{|c|c|c|c|c|c|c|c|c|}
\hline VARIABLE & $\mathbf{N}^{\circ}$ & $\%$ & $\mathbf{N}^{\circ}$ & $\%$ & OR & $\begin{array}{l}\text { IC } 9 \\
\text { LI }\end{array}$ & $\begin{aligned} & 5 \% \% \\
& \text { LS }\end{aligned}$ & Prueba p \\
\hline \multicolumn{9}{|c|}{ ¿Cree que usar el condón protege contra el SIDA? } \\
\hline & \multicolumn{2}{|c|}{ Sí } & \multicolumn{2}{|c|}{ No } & & & & \\
\hline Colegio público & 326 & 72 & 125 & 28 & 0,3 & 0,2 & 0,6 & 0,0001179 \\
\hline Colegio privado & \multicolumn{2}{|c|}{ Sí } & \multicolumn{2}{|c|}{ No sabe } & 0,3 & 0,2 & 0,0 & \\
\hline Colegio público & 326 & 70 & 140 & 30 & & & & \\
\hline Colegio privado & 121 & 78 & 35 & 22 & 0,1 & 0,4 & 1,0 & $0,06 / 4131$ \\
\hline & \multicolumn{2}{|c|}{ Sí } & \multicolumn{2}{|c|}{ No está seguro } & \multirow[b]{2}{*}{0,8} & \multirow[b]{2}{*}{0,6} & \multirow[b]{2}{*}{1,1} & \multirow[b]{2}{*}{0,1808709} \\
\hline $\begin{array}{l}\text { Colegio público } \\
\text { Colegio privado }\end{array}$ & $\begin{array}{l}326 \\
121\end{array}$ & $\begin{array}{l}48 \\
53\end{array}$ & $\begin{array}{l}357 \\
108\end{array}$ & $\begin{array}{l}52 \\
47\end{array}$ & & & & \\
\hline Ha tenido relaciones sexuales & \multicolumn{2}{|c|}{ Sí } & \multicolumn{2}{|c|}{ No } & \multirow{3}{*}{2,3} & \multirow{3}{*}{1,6} & \multirow[b]{3}{*}{3,4} & \multirow{3}{*}{0,0000077} \\
\hline Colegio público & 247 & 26 & 717 & 74 & & & & \\
\hline Colegio privado & 37 & 13 & 248 & 87 & & & & \\
\hline Protección en primera relación sexual & \multicolumn{2}{|c|}{ Sí } & \multicolumn{2}{|c|}{ No } & & & & \\
\hline Colegio público & 136 & 50 & 138 & 50 & & & & \\
\hline Colegio privado & 28 & 78 & 8 & 22 & 0,3 & 0,1 & 0,6 & $0,0014 / 10$ \\
\hline Ha sido golpeado en último año & & & & & & & & \\
\hline Colegio público & 283 & 31 & 631 & 69 & & & & \\
\hline Colegio privado & 82 & 29 & 204 & 71 & 1,1 & 0,8 & 1,5 & 0,4622526 \\
\hline Golpeó (pelea) a alguien el último año & & & & & & & & \\
\hline Colegio público & 279 & 30 & 635 & 69 & & & & \\
\hline Colegio privado & 64 & 22 & 221 & 78 & 1,5 & 1,1 & 2,1 & 0,0084950 \\
\hline $\begin{array}{l}\text { Lleva un arma rutinariamente para } \\
\text { defenderse }\end{array}$ & & & & & & & & \\
\hline Colegio público & 26 & 3 & 798 & 97 & & & & \\
\hline Colegio privado & 1 & 0,4 & 274 & 99,6 & 8,9 & 1,2 & 66,1 & 0,0096111 \\
\hline $\begin{array}{l}\text { Lleva un arma ocasionalmente para } \\
\text { defenderse }\end{array}$ & & & & & & & & \\
\hline Colegio público & 81 & 9 & 798 & 91 & & & & \\
\hline Colegio privado & 11 & 4 & 274 & 96 & 2,5 & 1,3 & 4,8 & 0,0035912 \\
\hline $\begin{array}{l}\text { Riesgo de trastorno de conducta } \\
\text { alimenticia }\end{array}$ & & & & & & & & \\
\hline Colegio público & 236 & 26 & 657 & 74 & & & & \\
\hline Colegio privado & 48 & 17 & 239 & 83 & 1,8 & 1,3 & 2,5 & 0,0008227 \\
\hline Beber en la última semana & & & & & & & & \\
\hline Colegio privado & 40 & 14 & 247 & 86 & & & & \\
\hline Colegio público & 291 & 30 & 667 & 70 & 0,4 & 0,3 & 0,5 & 0,0000000 \\
\hline Haber probado cigarrillo & & & & & & & & \\
\hline Colegio privado & 42 & 16 & 228 & 84 & & & & \\
\hline Colegio público & 274 & 32 & 576 & 68 & 0,4 & 0,3 & 0,0 & 0,0000001 \\
\hline Haber probado alcohol & & & & & & & & \\
\hline Colegio privado & 159 & 58 & 117 & 42 & & & & \\
\hline Colegio público & 488 & 55 & 407 & 45 & 1,1 & 0,9 & 1,5 & 0,3677496 \\
\hline Haber probado marihuana & & & & & & & & \\
\hline Colegio privado & 18 & 7 & 247 & 93 & & & & \\
\hline Colegio público & 172 & 21 & 646 & 79 & 0,3 & 0,2 & 0,5 & 0,0000001 \\
\hline $\begin{array}{l}\text { Tener amigos que beben o consumen } \\
\text { psicoactivos con frecuencia }\end{array}$ & & & & & & & & \\
\hline Colegio privado & 29 & 15 & 160 & 85 & & & & \\
\hline Colegio público & 128 & 24 & 411 & 76 & 0,6 & 0,4 & 0,9 & 0,0156441 \\
\hline Fumar en la actualidad & & & & & & & & \\
\hline Colegio privado & 7 & 3 & 268 & 97 & & & & \\
\hline Colegio público & 137 & 15 & 789 & 85 & 0,2 & 0,1 & 0,3 & 0,0000000 \\
\hline Beber en la actualidad & & & & & & & & \\
\hline Colegio privado & 46 & 17 & 230 & 83 & & & & \\
\hline Colegio público & 274 & 30 & 649 & 70 & 0,5 & 0,3 & 0,7 & 0,0000179 \\
\hline
\end{tabular}




\section{DISCUSIÓN}

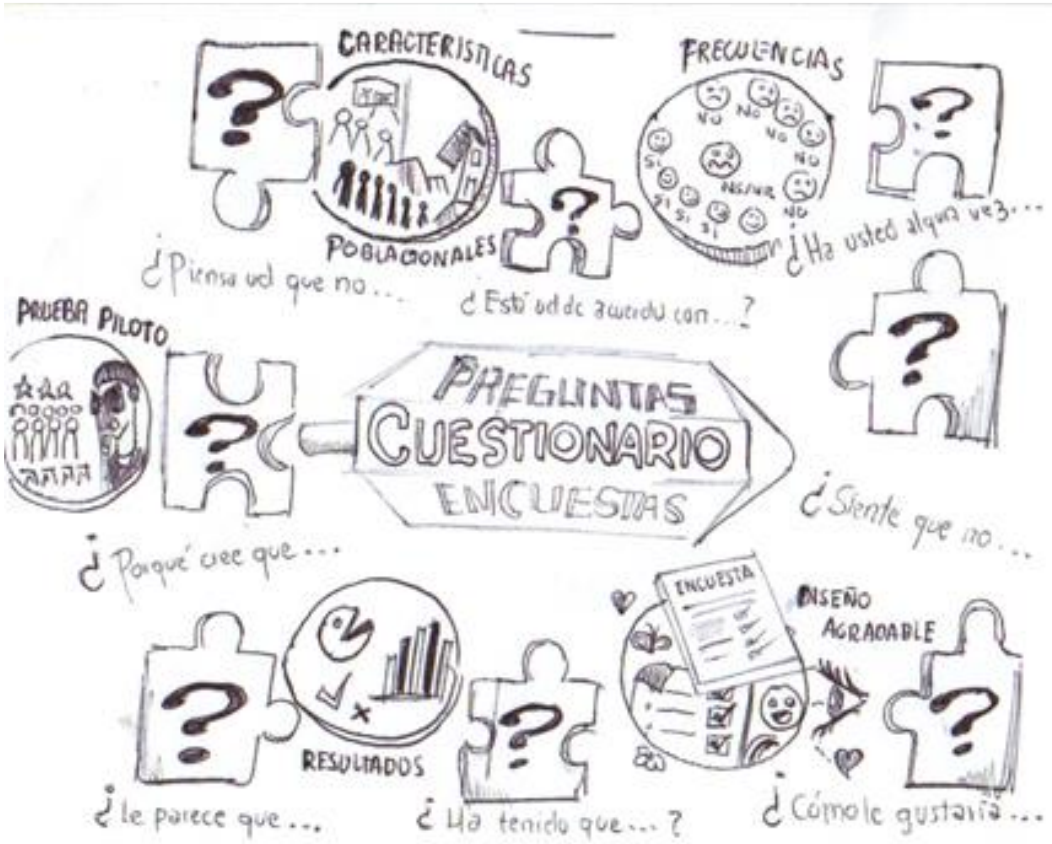

La presente investigación está sometida al sesgo de información por parte de los encuestados (¿habrán contestado la verdad?). Dicho sesgo se enfrentó asegurando la confidencialidad, la voluntariedad (si no querían no entregaban la encuesta) y solicitando a los profesores que se salieran del salón cuando los jóvenes estaban contestando. Sin embargo, resultó evidente que los jóvenes no se incomodaron y contestaron con gusto.

Una primera diferencia hallada es que los jóvenes del colegio con predominio de estrato 2 son un poco mayores que los del colegio que es en su mayoría de estrato 4. Es importante tener en cuenta esto pues la edad determina diferencias (a más edad, más comportamiento de riesgo), así como el ser hombre (29).

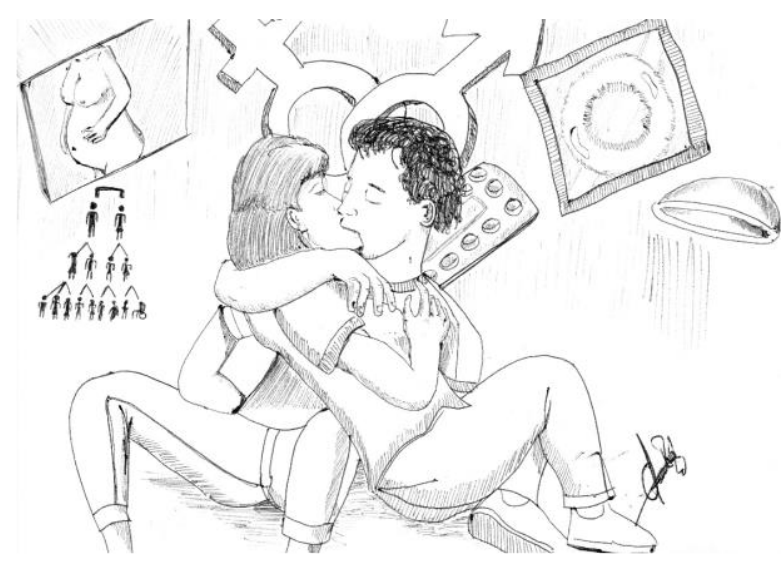

Teniendo en cuenta esas primeras diferencias en torno a la sexualidad, parece alarmante que exista una diferencia tan importante en torno al conocimiento acerca de la protección del condón (tabla 3). En el colegio de más baja condición socioeconómica los jóvenes creen menos en la protección del 
condón y esto los expone mucho más a los riesgos que conlleva el no usarlo. Tal situación no es exclusiva de esta investigación y ya ha sido detectada en los estudios de Profamilia (29) e incluso en otros (30). Si es como parece, una situación inequitativa y reiterativa (hipótesis: se educa menos a los más pobres), una explicación puede ser la mayor dificultad para abordar estos temas en estas familias y sus colegios. Preguntarse por qué sucede esto, resulta clave para poder proponer respuestas que disminuyan los riesgos en los más pobres. Este hallazgo se refuerza al observar que las relaciones sexuales y la protección en la primera relación, asumen diferencias de riesgo (tabla 3) para el colegio donde predominan los estratos inferiores. ¿Será que en el colegio de estratos bajos los profesores no abordan el asunto de la educación sexual de forma similar a los del colegio de mayor estrato? No se indagó, pero surge como otra explicación. A propósito de esto, la OMS ha elaborado una estrategia para expandir de forma más generalizada la atención de calidad contra las infecciones de transmisión sexual en el ámbito de la atención primaria, entre otros (31).

Algunos autores refieren que el que exista más disfunción familiar en los estratos más bajos puede ser un factor en esa complejidad de mayores riesgos en los más pobres (32). Se explicaría porque la disfunción familiar implica menos posibilidad de diálogo entre padres e hijos. González, en su artículo (33), pone de manifiesto interesantes aspectos a tener en cuenta en torno a los riesgos de sexualidad en adolecentes escolarizados de estratos 2 y 3 , donde la disfunción familiar, la mala comunicación con los padres y factores diferentes (aborto previo, etc.) han de tenerse en cuenta. En concordancia con esto, los resultados de esta investigación muestran que hay mayor percepción de disfuncionalidad familiar en el colegio donde predomina el estrato 2 (tabla 2), que en el colegio donde en su mayoría los estudiantes son de estrato 4.

En síntesis, en torno a la sexualidad, esta investigación pone de manifiesto diferencias que implican mayor riesgo en torno a lo que saben del condón y en los comportamientos en los más pobres, situación injusta que debe ser más estudiada para ser compensada debidamente (¿será igual en todas las situaciones de diferencia socioeconómica?).

Muy llamativos son los datos relacionados con los comportamientos violentos, en particular llevar un arma para defenderse (tabla 3), que en el colegio más pobre muestra unas diferencias muy importantes. Las razones Briceño (10) las explica muy bien y, aunque en el estudio no se indagó la ubicación geográfica donde viven los adolescentes, es muy evidente que los jóvenes del colegio de estratos más bajos viven en una zona de mayor riesgo delincuencial (34) con los factores asociados que de seguro coexisten en tal zona. Es muy probable que, en este grupo de jóvenes, llevar un arma sea, o bien porque han sido agredidos $(12,13,14)$ o, porque algunos ya están vinculados a pandillas 0 desarrollan prácticas delincuenciales (profesores del colegio de estratos 2 y 3 afirman que algunos jóvenes se dedican a expender drogas). ¿Cómo crear un ambiente escolar de más convivencia en colegios de estratos bajos? Esa es una pregunta que debe responderse $y$, al hacerlo y promover planes en tal sentido, una vez más se estará disminuyendo esta situación de desigualdad social que la

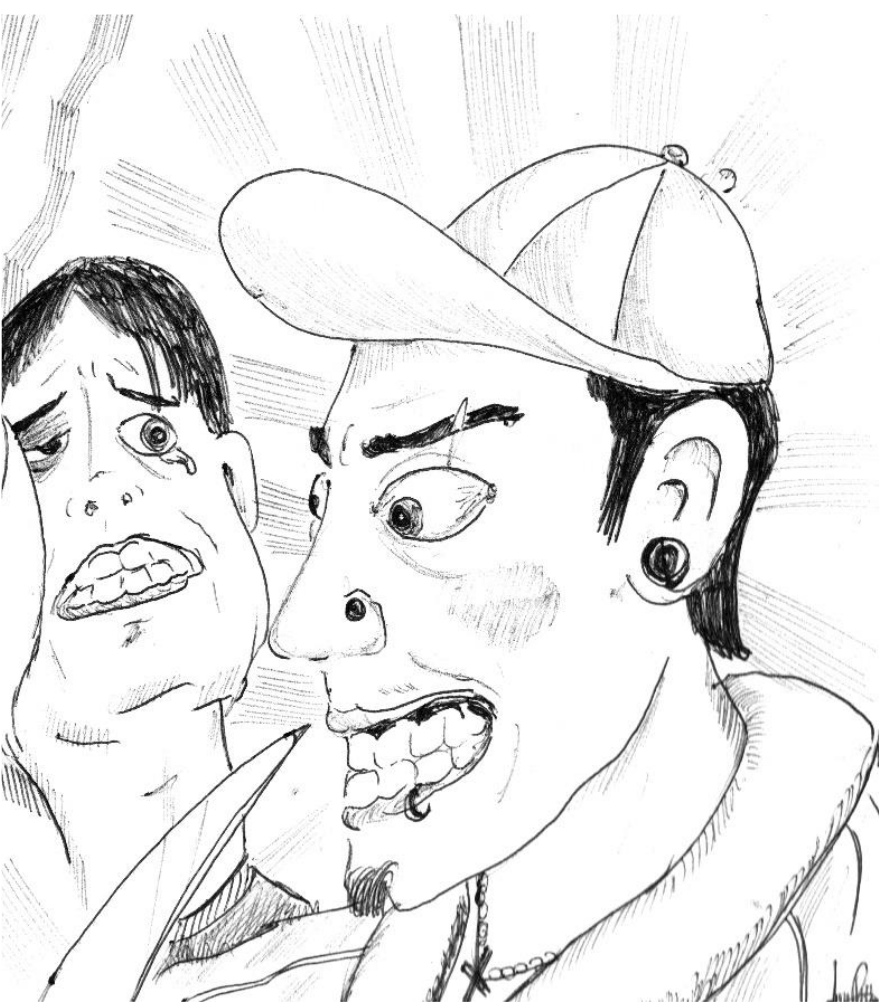
sociedad deberá compensar. 


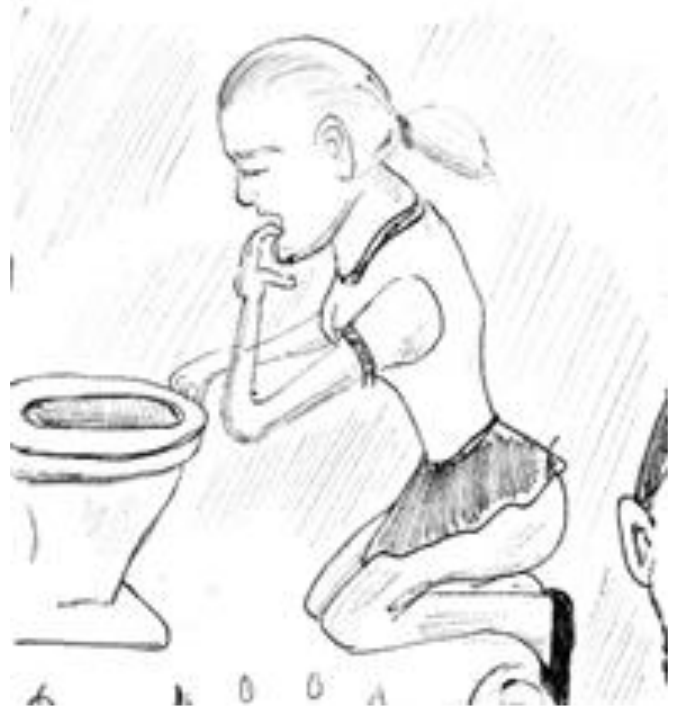

La tabla 3 pone de manifiesto que el riesgo de TCA está más presente en el colegio de estrato 2, si bien es necesario tener en cuenta que el test está validado en población femenina y no en masculina (3). Aunque se creía que los TCA eran un problema predominante de clases altas, han surgido investigaciones que ponen de manifiesto que están presentes en todas las condiciones (36), incluso con mayor prevalencia en las más bajas. Santocini (37) propone que la globalización, a través de los medios de comunicación, ha homogenizado ese supuesto "ideal" de lo que debe ser la figura humana. Piñeros (38) propone que la disfunción familiar, más presente en estratos bajos, guarda relación con la presencia de TCA, por ende, existe más riesgo.

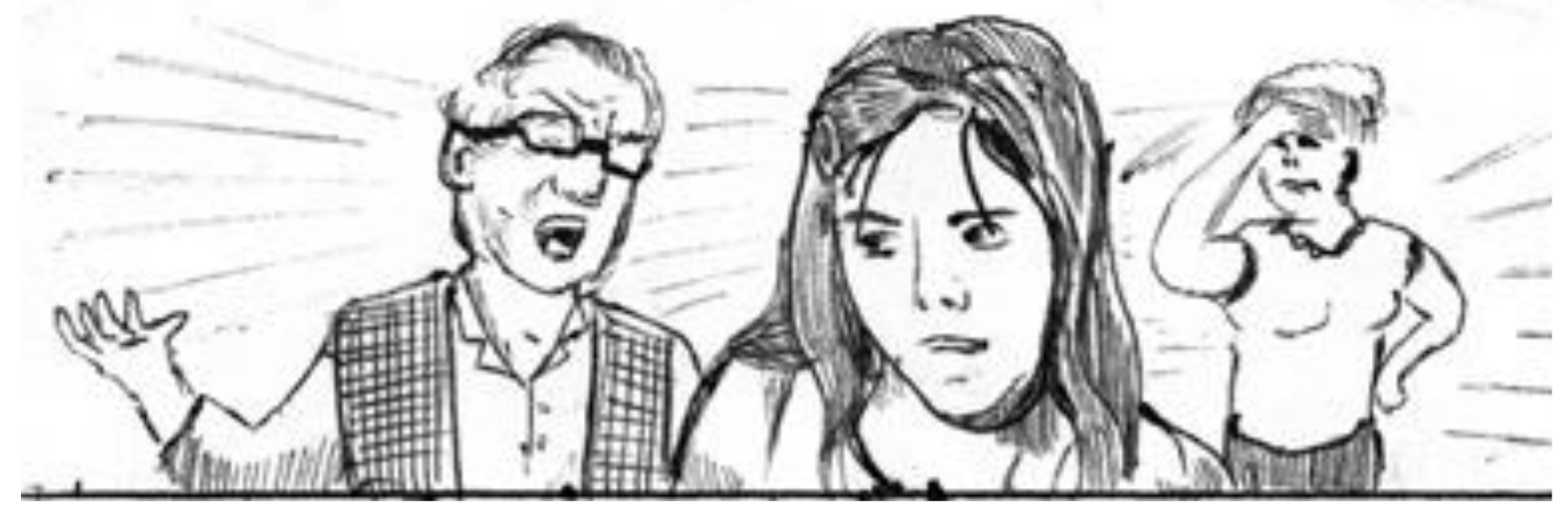

Esta situación la respaldan otros estudios, como el de Ruíz y otros (39) y, de ser confirmada, es una inmensa injusticia pues plantea que las familias de los más pobres están en una situación que les dificulta dar el respaldo que necesitan sus miembros y, de esa forma, estos se exponen a más riesgos. Implica, asimismo, la necesidad de intervenir de manera temprana en esas familias, buscando ofrecer posibilidades de desarrollo psicosocial que les permita a ellas y a sus miembros tener la oportunidad de ser una buena plataforma de lanzamiento. Nosotros creemos que es cierto; en las familias de los más pobres se presentan más situaciones de violencia y de disfuncionalidad. Ruíz y otros (39), 
mencionan que diversos autores relacionan a las familias de personas con anorexia nerviosa con una elevada implicación interpersonal, sobreprotección, rigidez y carencia de resolución de conflictos.

Una situación interesante se plantea al considerar los espacios deportivos de cada colegio estudiado en esta investigación. Cuando se aplicaron las encuestas se vio que el de estratos 2 y 3 los tenía restringidos (una cancha que se usa para baloncesto, voleibol y microfútbol) en tanto que en el colegio de estratos 4 y 5 existían canchas separadas y llenas de césped. Aunque no se preguntó, asumimos que igual será en cuanto al acceso a gimnasios. Si bien es cierto que el deporte se vincula con la salud, algunos estudios $(40,41)$ lo relacionan, por el contrario, con el favorecimiento para las manifestaciones de patologías alimentarias. Con razón, Moreno (41) advierte que las condiciones que pueden terminar en trastornos alimentarios son múltiples tantas como las posibilidades sociales a las que dan lugar. Estas diferencias de postura sugieren que es necesario seguir indagando.

Si bien no se indagó, la autoestima mucho tiene que ver con los TCA. Gismero (42) propone que en los jóvenes con riesgo de TCA está comprometida. Por ende, valdrá la pena indagar si la diferencia de estratos condiciona diferencias en torno a la autoestima (43).

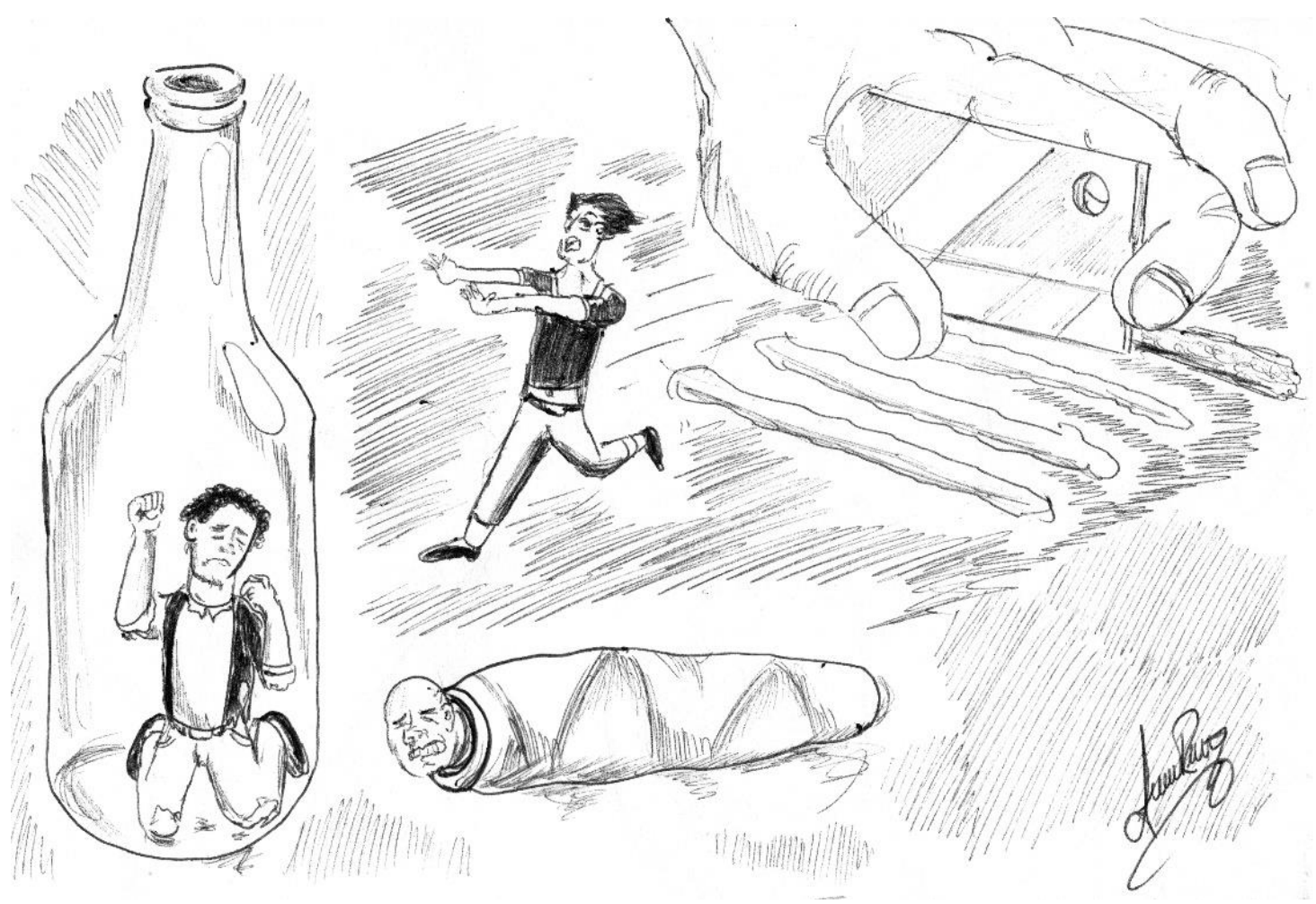

Otra vez se observa que los adolescentes del colegio de estratos 2 y 3 tienen más contacto con el alcohol y el tabaco que los de estratos 4 y 5 (tabla 3). Una revisión que se hizo sobre el tema mostró el concepto interesante de autoeficacia (44), entendida como una habilidad con la cual los jóvenes asumen comportamientos protectores. Planteamos que tal conducta está disminuida en los colegios de estratos más bajos. Tal vez por tener a su alrededor más influencia de jóvenes que asumen más riesgo, generando apego a redes sociales que, en vez de proteger, los exponen a más riesgo (45). Suponemos, a partir de la visión de los colegios a la que fuimos expuestos al aplicar las encuestas, que al menos en este caso, el ambiente escolar era más protector en el de estratos superiores que en el de estratos más bajos. 


\section{El abordaje}

¿Cómo será el abordaje de los problemas a que están expuestos los jóvenes en cada colegio? No lo indagamos, pero lo que vimos nos hace plantear, hipotéticamente, que en el colegio con predominio de estrato 4 se hace como parte del pensum, algo, incluso, recomendado por la OMS (46). Creemos que la supervisión de los padres es menor en el colegio de estratos más bajos, siendo esto un factor de riesgo bien identificado (47), pero reconocemos que no lo indagamos. Este trabajo muestra que los más pobres fuman y toman más. Bacigalipe (48) propone que, por recibir menos información, por el mal ejemplo de sus mayores, por tener menos control, por recibir más influencia de sus pares y por vivir bajo más estrés que los jóvenes de estrato más alto. Nosotros al reconocer la diferencia de la infraestructura de los planteles creemos que, además se estimula menos el deporte en los colegios de estrato más bajos y con eso, la evidente protección del mismo (49). Vale la pena resaltarlo porque el deporte, practicado en forma equilibrada, es un factor claramente protector para los jóvenes. Los colectivos permiten desarrollar procesos de comunicación y de gestión de conflictos, generan autoconfianza y, generan emociones fuertes y sanas. Existen trabajos que respaldan estas afirmaciones (50), en particular en lo relacionado con el cigarrillo y el alcohol. Lo cierto es que existen acciones de familia, integrándose con los colegios, que determinan protecciones para los jóvenes (51). Una vez más, creemos que estas acciones se hacen más en los colegios de estratos más altos, pero no lo preguntamos en nuestra encuesta.

\section{En conclusión...}

Esta comparación pone de manifiesto que los riesgos están más presentes en el colegio de estratos más bajos. Por supuesto que los hallazgos no permiten generalizarse, pero coinciden con los de buena parte de los artículos revisados. Si lo hallado es lo prevalente, es una inmensa injusticia que nuestra sociedad debe buscar cómo compensar, para tratar de acercarnos a una versión más equitativa de desarrollo.

Agradecimientos: a las directivas y alumnos de los dos colegios, quienes nos abrieron sus puertas con el fin de hacer posible esta investigación.

\section{REFERENCIAS}

(1) Krauskopf D. Juventud en riesgo y violencia. Presentación elaborada para el programa "Sociedad sin Violencia". Seminario permanente sobre violencia programa de las Naciones Unidas para el Desarrollo en El Salvador. Agosto, 2002.

(2) Burt M. Por qué debemos invertir en adolescentes. Fundación Kellogs Documento OPS; 1998.

(3) Forcier M, Blake D. Adolescent sexuality. Jul 21, 2016.

(4) Kancheva N, Bunupuradah T, Chaithongwonwatthana S. Contraceptive challenges in adolescents living with or at risk of HIV. J Virus Erad. 2016; 2(2):82-6.

(5) Ojeda G, Ordóñez M, Ochoa LH. Encuesta Nacional de Demografía y Salud 2010 [Internet]. Febrero 2011. Pp 120-147, 175. Disponible en:

https://www.minsalud.gov.co/sites/rid/Lists/BibliotecaDigital/RIDE/VS/ED/GCFI/Base\%20de\%20datos\%20ENDS\%2020 $10 \% 20$ informe.pdf

(6) Flórez CE, Vargas E, Henao J, González C, Soto V, Kassem D. Fecundidad adolescente en Colombia: Incidencia, tendencias y determinantes. Un enfoque de historia de vida [Internet]. Documento CEDE 2004-31; agosto de 2004. Disponible en: https://economia.uniandes.edu.co/assets/archivos/Documentos_CEDE/d2004-31.pdf)

(7) Galindo PC. Análisis del embarazo y la maternidad durante la adolescencia: diferencias socioeconómicas. Revista desarrollo y sociedad [Internet]. 2012; (69)133-185. Disponible en:

https://economia.uniandes.edu.co/publicaciones/revista-desarrollo-y-sociedad/no-69/analisis-del-embarazo-y-lamaternidad-durante-la-adolescencia-diferencias-a-nivel-socioeconomico

(8) Who.int [Internet]. Violencia juvenil. 2016 [actualizado julio de 2016; citado 16 agosto de 2016]. Disponible en: http://www.who.int/mediacentre/factsheets/fs356/es/\#.

(9) Dane.gov.co [Internet]. Bogotá D.C: Departamento Administrativo Nacional de Estadística (DANE); 2011 [actualizado 9 de mayo de 2012; citado 16 de agosto de 2016]. Disponible en: http://www.dane.gov.co/files/investigaciones/boletines/educacion/bol_ConvivenciaEscolar_2011.pdf 
(10) Briceño R. Villaveces A. Eastman C. Understanding the uneven distribution of the incidence of homicide in Latin America. Int J Epidemiol [Internet]. 2008 [08 de septiembre de 2016]; 37 (4): 751-7. Disponible en: http://ije.oxfordjournals.org/content/37/4/751.full.pdf+html.

(11) Logan J, Vagi K, Gorman D. Characteristics of Youth with Combined Histories of Violent Behavior, Suicidal Ideation or Behavior, and Gun-Carrying. Crisis [Internet]. 2016 [16 de agosto de 2016]. Disponible en: https://www.researchgate.net/publication/303740472_Characteristics_of_Youth_With_Combined_Histories_of_Violent_B ehavior_Suicidal_Ideation_or_Behavior_and_Gun-Carrying

(12) Ruggles K. Rajan, S. Gun Possession among American Youth: A Discovery-Based Approach to Understand Gun Violence. PLoS ONE [Internet]. 2014 [16 de agosto de 2016]; 9(11): 1 - 12. Disponible en: http://www.ncbi.nlm.nih.gov/pmc/articles/PMC4221159/pdf/pone.0111893.pdf

(13) Pickett W, Molcho M, Elgar F, Brooks F, De Looze M, Rathmann K, et al. Trends and Socioeconomic Correlates of Adolescent Physical Fighting in 30 Countries. Pediatrics [Internet]. 2013 [16 de agosto de 2016]; 131 (1): 18-26. Disponible en: http://pediatrics.aappublications.org/content/131/1/e18.long

(14) Sharma B, Nam E, Kim H, Koo J. The Influence of Witnessing Inter-parental Violence and Bullying Victimization in Involvement in Fighting among Adolescents: Evidence from a School-based Cross-sectional Survey in Peru. J Lifestyle Med [Internet]. 2016 [16 de agosto de 2016]; 6 (1): 27-35. Disponible en: https://www.ncbi.nlm.nih.gov/pmc/articles/PMC4915764/pdf/jlm-6-027.pdf

(15) Kreipe R. Trastornos de conducta alimentaria. Ed. Elsevier. España. SLU Tratado de Pediatría. Cap 28. P. 170 - 179. Copyright 2016.

(16) Marin V. Eating Disorders of School Children and Adolescents. Unidad de Nutrición Clínica. Instituto de Nutrición y Tecnología de los Alimentos (INTA). 2002; 29(2). Universidad de Chile. Versión On-line 0717 - 7518. [26 de agosto de 2016]. Disponible en: http://www.scielo.cl/scielo.php?pid=S0717-75182002000200002\&script=sci_arttext ${ }^{*}$

(17) López J, Valdés M. DSM IV: Manual de diagnóstico y estadístico de los trastornos mentales. $4^{\circ}$ edición. Barcelona. Ed. MASSON S.A. (2002), [26 de agosto de 2016]. Disponible en: https://catedraedipica.files. wordpress.com/2010/02/trastornos-de-la-conducta-alimentaria-dsm-iv.pdf

(18) Moreno M, Ortiz G. Eating Disorder and its Relationship with Body Image and Self-Esteem in Adolescents. Universidad Veracruzana, México. Terapia Psicológica. 2009; 27(2). Versión On-line ISSN 0718-4808. [26 de agosto de 2016]. Disponible en: http://www.scielo.cl/scielo.php?script=sci_arttext\&pid=S0718-48082009000200004

(19) Aramburu M, Guerra J. Autoconcepto: dimensiones, origen, funciones, incongruencias, cambios y consistencia. Interpsiquis. 2001; 2: 246-249. [27 de agosto de 2016]. Disponible en: http://www.scielo.cl/scielo.php?script=sci_nlinks\&ref=8527689\&pid=S0718-4808200900020000400004\&lng=es

(20) Unikel SC. Conductas alimentarias de riesgo en adolescentes mexicanos. Datos en población estudiantil del DF, México. Revista de Investigación Científica. 2000; 52(2): 140-147. [27 de agosto de 2016]. Disponible en: http://www.scielo.cl/scielo.php?script=sci_nlinks\&ref=8527724\&pid=S0718-4808200900020000400039\&lng=es

(21) Montero P, Morales EM, Carbajal A. (2004) Valoración de la percepción de la imagen corporal mediante modelos anatómicos. Antropología, 8, 107-116. [27 de agosto de 2016]. Disponible en: http://www.didac.ehu.es/antropo/8/88/Montero.pdf

(22) Ministerio de Salud y Protección Social y Universidad Nacional de Colombia. Estrategia Nacional de Respuesta Integral Frente al Consumo de Alcohol en Colombia. 2013. [citado 28 agosto del 2016]. Disponible en: https://www.minsalud.gov.co/sites/rid/Lists/BibliotecaDigital/RIDE/VS/PP/ENT/estrategia-nacional-alcohol-colombia.pdf

(23) Gobierno Nacional de la República de Colombia. Estudio Nacional de Consumo de Sustancias Psicoactivas en Población Escolar Colombia. 2011. Colombia: Lisseth Ángel Valencia, pp.53-60.

(24) El Tiempo (2006). La Policía encontró mil menores en dos 'chiquitecas' de Suba y selló los establecimientos. Mayo 7.

(25) Cicua D, Méndez M, Muñoz L. Factores en el consumo de alcohol en adolescentes. Rev. Pensamiento Psicológico. 2008; 4: 115-134. Disponible en: http://revistas.javerianacali.edu.co/index.php/pensamientopsicologico/article/view/83/247

(26) Sigampa J, Ferriani M, Nakano A. Factores protectores frente al consumo de alcohol: concepción de maestros de nivel inicial. Revista Latinoamericana de Enfermagem [Internet]. 2005 [citado 28 agosto del 2016]; 13(spe), pp.771-777.

(27) Álvarez A, Alonso M, Zanetti A. Alcohol consumption and self-esteem in adolescents. Revista Latinoamericana de Enfermagem. 2010; 18(SPE): 634-640. Disponible en: http://www.scielo.br/scielo.php?script=sci_arttext\&pid=S010411692010000700021

(28) Santander S, Zubarew T, Santelices L, Argollo P, Cerda J, Bórquez M. Influencia de la familia como factor protector de conductas de riesgo en escolares chilenos. [Internet]. Revista médica de Chile [citado 12 septiembre de 2016]. 2008; 136(3): 317-324. Disponible en: http://www.scielo.cl/scielo.php?script=sci_arttext\&pid=S0034-98872008000300006

(29) Ojeda G, Ordóñez M, Ochoa LH. Encuesta Nacional de Demografía y Salud 2010. Febrero 2011. Pp 120-147

(30) Galindo PC. Análisis del embarazo y la maternidad durante la adolescencia: diferencias socioeconómicas. Revista desarrollo y sociedad; 2012; (69)133-185.

(31) Organización Mundial de la Salud (OMS). Estrategia Mundial de Prevención y Control de las Infecciones de Transmisión Sexual 2006-2015. OMS; 2007. Report: WC142.

(32) Vinaccia S, Quiceno M, Gaviria S. Conductas sexuales de riesgo para la infección por VIH/SIDA en adolescentes colombianos. Terapia psicológica. 2007; 25(1): 39-50.

(33) González JC, Salamanca J, Quiroz R, Hernández A, Hernández AD, Quesada B. Identificación de factores de riesgo de embarazo en población adolescente escolar urbana y rural colombiana. Rev. salud pública [Internet]. 2012; [citado 13 
de noviembre de 2016]; 14(3): 404-416. Disponible en:

http://www.scielo.org.co/scielo.php?script=sci_arttext\&pid=S0124-00642012000300004\&lng=en.

(34) Nullvalue. Lisboa, una bomba de tiempo en Suba. El Tiempo [Internet]. Domingo 7 de marzo de 2010. Archivo. Disponible en: http://www.eltiempo.com/archivo/documento/MAM-3870465

(35) Muro $\mathrm{P}$, Amador F. Scoff-c: Propiedades psicométricas de la versión en catalán en una muestra de adolescentes españoles. j psychosom res. 2008; 64 (1): 81-6.

(36) Morandé G. Aspectos socioeconómicos y trastornos alimentarios. De la desnutrición a la opulencia. 2005; 30-38. [3 septiembre de 2016]. Disponible en: http://www.tcasevilla.com/archivos/aspectos_socio_economicos_y_trastornos_alimentarios._de_la_desnutricion_a_la_o pulencia._.doc

(37) Santocini C, Caballero A. Guía clínica para trastornos de conducta alimentaria. 2010; 37, 38,39. Disponible en: http://www.inprf.gob.mx/opencms/export/sites/INPRFM/psicosociales/archivos/guias/trastornos_alimentacion.pdf

(38) Piñeros S, Molano J, López C. Factores de riesgo de los trastornos de la conducta alimentaria en jóvenes escolarizados en Cundinamarca (Colombia). Rev. Colomb. Psiquiat. 2010; 39(2). Disponible en: http://www.scielo.org.co/pdf/rcp/v39n2/v39n2a07.pdf

(39) Ruíz AO, Vázquez R, Mancilla JM, Viladrich C, Halley ME. Factores familiares asociados a los trastornos alimentarios: una revisión. Revista Mexicana de Trastornos Alimentarios/Mexican Journal of Eating Disorders. 2013; 4(1): 45-57. [10 septiembre de 2016]. Disponible en http://www.scielo.org.mx/scielo.php?script=sci_arttext\&pid=S200715232013000100006

(40) Behar R, Hernández P. Deportes y trastornos de la conducta alimentaria. Rev. Méd. Chile. 2002; 130(3). Disponible en: http://dx.doi.org/10.4067/S0034-98872002000300007

(41) Moreno J. Moral corporal, trastornos alimentarios y clase social. Centro de investigaciones sociológicas. $1^{a}$ edición. Consejo editorial de la colección monografías y colección academia; 2010. [04 de septiembre de 2016]. Disponible en: https://books.google.com.co/books?id=JN-

XkGc2FZEC\&pg =PR4\&lpg =PR4\&dq=Moreno+J.+Moral+corporal, +trastornos+alimentarios+y+clase+social. +Centro+de+ investigaciones+sociol\%C3\%B3gicas. $+1 \% \mathrm{C} 2 \% \mathrm{AA}+$ edici $\% \mathrm{C} 3 \% \mathrm{~B} 3 \mathrm{n}$. +Consejo+editorial+de+la+colecci\%C3\%B3n+mono graf\%C3\%ADas $+y+$ colecci\%C3\%B3n+academia; $+2010 \&$ source=bl\&ots=rcXf4St7ur\&sig=x2jBgQrGNDWEZINRO0oaeJW $\mathrm{S} 6 \mathrm{qg} \& \mathrm{hl}=\mathrm{es} \& \mathrm{sa}=$ X\&ved=0ahUKEwiA8fGqtIDRAhUBSSYKHfIKCHgQ6AEIGzAA\#v=onepage\&q=deporte\&f=false

(42) Gismero E. Evaluación del autoconcepto, la satisfacción con el propio cuerpo y las habilidades sociales en la anorexia y bulimia nerviosas. Clínica y Salud. 2001; 12(3): 289-304. [04 de septiembre de 2016]. Disponible en http://www.redalyc.org/html/1806/180618319001/

(43) Cetraro P. Trastornos de alimentación, imagen corporal y autoestima en adolescentes. [Tesis]. Argentina: Universidad Abierta Interamericana. Sede Regional Rosario. Facultad de Psicología y Relaciones Humanas; 2011.

(44) Olivari C, Barra E. Influencia de la autoeficacia y la autoestima en la conducta de fumar en adolescentes. Sociedad chilena de psicología. 2005; 23(2): 5-11.

(45) Urzúa R. Conductas de riesgo en adolescentes y factores protectores. Escuela de Medicina Puc SF [citado 2 de septiembre de 2016]. Disponible en: http://escuela.med.puc.cl/paginas/ops/curso/lecciones/leccion16/m4l16leccion2.html

(46) The World Health Organization. Skills for health [Internet]. Disponible en: http://www.who.int/school_youth_health/media/en/sch_skills4health_03.pdf

(47) National Institute on Drug Abuse en español (NIDA). ¿Cuáles son las señales tempranas de riesgo que pueden predecir el abuso de drogas en el futuro? (2004). Disponible en: https://www.drugabuse.gov/es/publicaciones/como-prevenir-eluso-de-drogas/capitulo-1-los-factores-de-riesgo-y-los-factores-de-proteccion/cuales-son-las-se

(48) Bacigalupe A. Esnaola S, Martín U. (2011). Evolución de la prevalencia y las desigualdades socia- les del consumo de tabaco en la C.A de Euskadi: 1986-2007. Vitoria-Gasteiz: Departamento de Sanidad y Consumo. Disponible en: http://www.osakidetza.euskadi.eus/contenidos/informacion/publicaciones_informes_estudio/es_pub/adjuntos/Osagin\%2 0Txostenak\%202011-1.pdf

(49) Oficina de las Naciones Unidas contra la Droga y el Delito. El deporte como instrumento de prevención del uso indebido de drogas. 2003. [citado 09 septiembre de 2016]. Disponible en: https://www.unodc.org/pdf/youthnet/handbook_sport_spanish.pdf

(50) Ruiz JF, Cruz E, García ME. Motivos para la práctica deportiva y su relación con el consumo de alcohol y tabaco en jóvenes españoles. Salud pública Méx [revista en la Internet]. 2009 [citado 11 de septiembre de 2016]; 51(6): 496-504. Disponible en: http://www.scielo.org.mx/scielo.php?script=sci_arttext\&pid=S0036-36342009000600008\&lng=es.

(51) López S, Rodríguez PJL. Factores de riesgo y de protección en el consumo de drogas y la conducta antisocial en adolescentes y jóvenes españoles. International Journal of Psychological Research. 2012; 5(1): 25-33. Disponible en: http://www.redalyc.org:9081/articulo.oa?id=299023539004

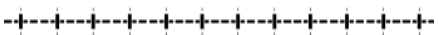

